\title{
On Intuitionistic Fuzzy Weakly Generalized Closed Set and its Applications
}

\author{
P. Rajarajeswari \\ Assistant Professor, Department of Mathematics \\ Chikkanna Government Arts College \\ Tirupur-641 602
}

\author{
R. Krishna Moorthy \\ Assistant Professor, Department of Mathematics \\ Kumaraguru College of Technology \\ Coimbatore-641 049
}

\begin{abstract}
The purpose of this paper is to introduce and study the concepts of intuitionistic fuzzy weakly generalized closed set and intuitionistic fuzzy weakly generalized open set in intuitionistic fuzzy topological space. We investigate some of their properties. Also we study the application of intuitionistic fuzzy weakly generalized closed set namely intuitionistic fuzzy ${ }_{w} T_{1 / 2}$ space and intuitionistic fuzzy ${ }_{w g} T_{q}$ space.
\end{abstract}

\section{Keywords}

Intuitionistic fuzzy topology, Intuitionistic fuzzy weakly generalized closed set, Intuitionistic fuzzy weakly generalized open set, Intuitionistic fuzzy ${ }_{w} T_{1 / 2}$ space and Intuitionistic fuzzy ${ }_{w g} T_{q}$ space.

\section{AMS Subject Classification (2000): 54A40, 03F55}

\section{INTRODUCTION}

Fuzzy set(FS), proposed by Zadeh [14] in 1965, as a framework to encounter uncertainity, vagueness and partial truth , represents a degree of membership for each member of the universe of discourse to a subset of it. Later on, fuzzy topology was introduced by Chang [3] in 1967.By adding the degree of non-membership to FS, Atanassov [1] proposed intuitionistic fuzzy set (IFS) in 1983 which looks more accurately to uncertainity quantification and provides the opportunity to precisely model the problem based on the existing knowledge and observations. After this, there have been several generalizations of notions of fuzzy sets and fuzzy topology. In the last few years various concepts in fuzzy were extended to intuitionistic fuzzy sets. In 1997, Coker [4] introduced the concept of intuitionistic fuzzy topological space. In this paper, we introduce one of the concepts namely weakly generalized closed set which were introduced initially by N.Nagaveni [8] in General Topology in 1999. After this many researchers worked on this set and developed many interesting properties and applications. We have studied some of the basic properties regarding it. We also introduced the applications of intuitionistic fuzzy weakly generalized closed set namely intuitionistic fuzzy ${ }_{\text {w }} \mathrm{T}_{1 / 2}$ space, intuitionistic fuzzy ${ }_{w g} T_{q}$ space and obtained some characterizations and several preservation theorems of such spaces.

\section{PRELIMINARIES}

Definition 2.1: [1] Let $X$ be a non empty fixed set. An intuitionistic fuzzy set (IFS in short) $\mathrm{A}$ in $\mathrm{X}$ is an object having the form $\mathrm{A}=\left\{\left\langle\mathrm{x}, \mu_{\mathrm{A}}(\mathrm{x}), v_{\mathrm{A}}(\mathrm{x})\right\rangle / \mathrm{x} \in \mathrm{X}\right\}$ where the functions $\mu_{\mathrm{A}}(\mathrm{x}): \mathrm{X} \rightarrow[0,1]$ and $v_{\mathrm{A}}(\mathrm{x}): \mathrm{X} \rightarrow[0,1]$ denote the degree of membership (namely $\mu_{\mathrm{A}}(\mathrm{x})$ ) and the degree of nonmembership (namely $v_{\mathrm{A}}(\mathrm{x})$ ) of each element $\mathrm{x} \in \mathrm{X}$ to the set $\mathrm{A}$ respectively and $0 \leq \mu_{A}(x)+v_{A}(x) \leq 1$ for each $x \in X$.

Definition 2.2: [1] Let A and B be IFS's of the forms $\mathrm{A}=\left\{\left\langle\mathrm{x}, \mu_{\mathrm{A}}(\mathrm{x}), v_{\mathrm{A}}(\mathrm{x})\right\rangle / \mathrm{x} \in \mathrm{X}\right\}$ and

$\mathrm{B}=\left\{\left\langle\mathrm{x}, \mu_{\mathrm{B}}(\mathrm{x}), v_{\mathrm{B}}(\mathrm{x})\right\rangle / \mathrm{x} \in \mathrm{X}\right\}$. Then

(a) $\mathrm{A} \subseteq \mathrm{B}$ if and only if $\mu_{\mathrm{A}}(\mathrm{x}) \leq \mu_{\mathrm{B}}(\mathrm{x})$ and $v_{\mathrm{A}}(\mathrm{x}) \geq v_{\mathrm{B}}(\mathrm{x})$ for all $\mathrm{x} \in \mathrm{X}$,

(b) $\mathrm{A}=\mathrm{B}$ if and only if $\mathrm{A} \subseteq \mathrm{B}$ and $\mathrm{B} \subseteq \mathrm{A}$,

(c) $A^{c}=\left\{\left\langle x, v_{A}(x), \mu_{A}(x)\right\rangle / x \in X\right\}$,

(d) $\mathrm{A} \cap \mathrm{B}=\left\{\left\langle\mathrm{x}, \mu_{\mathrm{A}}(\mathrm{x}) \wedge \mu_{\mathrm{B}}(\mathrm{x}), v_{\mathrm{A}}(\mathrm{x}) \vee v_{\mathrm{B}}(\mathrm{x})\right\rangle / \mathrm{x} \in \mathrm{X}\right\}$,

(e) $\mathrm{A} \cup \mathrm{B}=\left\{\left\langle\mathrm{x}, \mu_{\mathrm{A}}(\mathrm{x}) \vee \mu_{\mathrm{B}}(\mathrm{x}), v_{\mathrm{A}}(\mathrm{x}) \wedge v_{\mathrm{B}}(\mathrm{x})\right\rangle / \mathrm{x} \in \mathrm{X}\right\}$

For the sake of simplicity, we shall use the notation $\mathrm{A}=\left\langle\mathrm{x}, \mu_{\mathrm{A}}, v_{\mathrm{A}}\right\rangle$ instead of $\mathrm{A}=\left\{\left\langle\mathrm{x}, \mu_{\mathrm{A}}(\mathrm{x}), v_{\mathrm{A}}(\mathrm{x})\right\rangle / \mathrm{x} \in \mathrm{X}\right\}$. Also for the sake of simplicity, we shall use the notation $\mathrm{A}=\left\langle\mathrm{x}, \quad\left(\mu_{\mathrm{A}}, \mu_{\mathrm{B}}\right), \quad\left(v_{\mathrm{A}}, v_{\mathrm{B}}\right)\right\rangle$ instead of $\mathrm{A}=\left\langle\mathrm{x},\left(\mathrm{A} / \mu_{\mathrm{A}}, \mathrm{B} / \mu_{\mathrm{B}}\right),\left(\mathrm{A} / v_{\mathrm{A}}, \mathrm{B} / v_{\mathrm{B}}\right)\right\rangle$.

The intuitionistic fuzzy sets $0_{\sim}=\{\langle\mathrm{x}, 0,1\rangle / \mathrm{x} \in \mathrm{X}\}$ and $1_{\sim}=\{\langle\mathrm{x}, 1,0\rangle / \mathrm{x} \in \mathrm{X}\}$ are respectively the empty set and the whole set of $X$.

Definition 2.3: [4] An intuitionistic fuzzy topology (IFT in short) on a non empty $\mathrm{X}$ is a family $\tau$ of IFS in X satisfying the following axioms:

(a) $0_{\sim}, 1_{\sim} \in \tau$,

(b) $\mathrm{G}_{1} \cap \mathrm{G}_{2} \in \tau$, for any $\mathrm{G}_{1}, \mathrm{G}_{2} \in \tau$,

(c) $\cup \mathrm{G}_{\mathrm{i}} \in \tau$ for any arbitrary family $\left\{\mathrm{G}_{\mathrm{i}} / \mathrm{i} \in \mathrm{J}\right\} \subseteq \tau$.

In this case the pair $(\mathrm{X}, \tau)$ is called an intuitionistic fuzzy topological space (IFTS in short) and any IFS in $\tau$ is known as an intuitionistic fuzzy open set (IFOS for short) in X.

The complement $\mathrm{A}^{\mathrm{c}}$ of an $\operatorname{IFOS} \mathrm{A}$ in an $\operatorname{IFTS}(\mathrm{X}, \tau)$ is called an intuitionistic fuzzy closed set (IFCS for short) in X. 
Definition 2.4: [4] Let $(X, \tau)$ be an IFTS and $A=\left\langle x, \mu_{A}, v_{A}\right\rangle$ be an IFS in $X$. Then the intuitionistic fuzzy interior and an intuitionistic fuzzy closure are defined by

$\operatorname{int}(\mathrm{A})=\cup\{\mathrm{G} / \mathrm{G}$ is an IFOS in $\mathrm{X}$ and $\mathrm{G} \subseteq \mathrm{A}\}$,

$\mathrm{cl}(\mathrm{A})=\cap\{\mathrm{K} / \mathrm{K}$ is an IFCS in $\mathrm{X}$ and $\mathrm{A} \subseteq \mathrm{K}\}$.

Result 2.5: [4] Let A and B be any two intuitionistic fuzzy sets of an intuitionistic fuzzy topological space $(X, \tau)$.Then

(a) $\mathrm{A}$ is an intuitionistic fuzzy closed set in $\mathrm{X} \Leftrightarrow \operatorname{cl}(\mathrm{A})=\mathrm{A}$,

(b) $\mathrm{A}$ is an intuitionistic fuzzy open set in $\mathrm{X} \Leftrightarrow \operatorname{int}(\mathrm{A})=\mathrm{A}$,

(c) $\operatorname{cl}\left(\mathrm{A}^{\mathrm{c}}\right)=(\operatorname{int}(\mathrm{A}))^{\mathrm{c}}$,

(d) $\operatorname{int}\left(\mathrm{A}^{\mathrm{c}}\right)=(\mathrm{cl}(\mathrm{A}))^{\mathrm{C}}$,

(e) $\mathrm{A} \subseteq \mathrm{B} \Rightarrow \operatorname{int}(\mathrm{A}) \subseteq \operatorname{int}(\mathrm{B})$,

(f) $\mathrm{A} \subseteq \mathrm{B} \Rightarrow \operatorname{cl}(\mathrm{A}) \subseteq \mathrm{cl}(\mathrm{B})$,

$(\mathrm{g}) \operatorname{cl}(\mathrm{A} \cup \mathrm{B})=\operatorname{cl}(\mathrm{A}) \cup \operatorname{cl}(\mathrm{B})$,

(h) $\operatorname{int}(\mathrm{A} \cap \mathrm{B})=\operatorname{int}(\mathrm{A}) \cap \operatorname{int}(\mathrm{B})$

Definition 2.6: [13] Let $(X, \tau)$ be an IFTS and $A=\left\langle x, \mu_{A}, v_{A}\right\rangle$ be an IFS in X. Then the semi closure of $A(\operatorname{scl}(A)$ in short) and semi interior of $\mathrm{A}(\operatorname{sint}(\mathrm{A})$ in short) are defined as

$\operatorname{sint}(A)=\cup\{G / G$ is an IFSOS in $X$ and $G \subseteq A\}$,

$\operatorname{scl}(\mathrm{A})=\cap\{\mathrm{K} / \mathrm{K}$ is an IFSCS in $\mathrm{X}$ and $\mathrm{A} \subseteq \mathrm{K}\}$.

Result 2.7: [11] Let $A$ be an IFS in $(X, \tau)$, then

(i) $\operatorname{scl}(\mathrm{A})=\mathrm{A} \cup \operatorname{int}(\mathrm{cl}(\mathrm{A}))$,

(ii) $\operatorname{sint}(\mathrm{A})=\mathrm{A} \cap \mathrm{cl}(\mathrm{int}(\mathrm{A}))$.

Definition 2.8: [9] Let $(X, \tau)$ be an IFTS and $A=\left\langle x, \mu_{A}, v_{A}\right\rangle$ be an IFS in X. Then the alpha closure of $\mathrm{A}(\alpha \mathrm{cl}(\mathrm{A})$ in short) and alpha interior of $\mathrm{A}(\alpha \operatorname{int}(\mathrm{A})$ in short) are defined as

$\operatorname{\alpha int}(\mathrm{A})=\cup\{\mathrm{G} / \mathrm{G}$ is an IF $\alpha \mathrm{OS}$ in $\mathrm{X}$ and $\mathrm{G} \subseteq \mathrm{A}\}$,

$\alpha \operatorname{cl}(\mathrm{A})=\cap\{\mathrm{K} / \mathrm{K}$ is an IF $\alpha \mathrm{CS}$ in $\mathrm{X}$ and $\mathrm{A} \subseteq \mathrm{K}\}$.

Result 2.9: [9] Let $A$ be an IFS in $(X, \tau)$, then

(i) $\alpha \operatorname{cl}(\mathrm{A})=\mathrm{A} \cup \operatorname{cl}(\operatorname{int}(\mathrm{cl}(\mathrm{A})))$,

(ii) $\alpha \operatorname{int}(\mathrm{A})=\mathrm{A} \cap \operatorname{int}(\mathrm{cl}(\operatorname{int}(\mathrm{A})))$.

Definition 2.10: An IFS $A=\left\{\left\langle x, \mu_{A}(x), v_{A}(x)\right\rangle / x \in X\right\}$ in an $\operatorname{IFTS}(\mathrm{X}, \tau)$ is called an

(a)intuitionistic fuzzy semi closed set [5] (IFSCS) if $\operatorname{int}(\operatorname{cl}(\mathrm{A})) \subseteq \mathrm{A}$,

(b)intuitionistic fuzzy $\alpha$-closed set [5] (IF $\alpha \mathrm{CS})$ if $\operatorname{cl}(\operatorname{int}(\operatorname{cl}(\mathrm{A}))) \subseteq \mathrm{A}$,

(c)intuitionistic fuzzy pre-closed set [5] (IFPCS) if $\mathrm{cl}(\operatorname{int}(\mathrm{A})) \subseteq \mathrm{A}$,

(d)intuitionistic fuzzy regular closed set [5] (IFRCS) if $\operatorname{cl}(\operatorname{int}(\mathrm{A}))=\mathrm{A}$, (e)intuitionistic fuzzy generalized closed set [12] (IFGCS) if $\mathrm{cl}(\mathrm{A}) \subseteq \mathrm{U}$ whenever $\mathrm{A} \subseteq \mathrm{U}$ and $\mathrm{U}$ is an IFOS,

(f)intuitionistic fuzzy generalized semi closed set [10] (IFGSCS) if $\operatorname{scl}(\mathrm{A}) \subseteq \mathrm{U}$ whenever $\mathrm{A} \subseteq \mathrm{U}$ and $\mathrm{U}$ is an IFOS,

(g)intuitionistic fuzzy $\alpha$ generalized closed set [9] (IF $\alpha \mathrm{GCS}$ ) if $\alpha \mathrm{cl}(\mathrm{A}) \subseteq \mathrm{U}$, whenever $\mathrm{A} \subseteq \mathrm{U}$ and $\mathrm{U}$ is an IFOS.

An IFS A is called intuitionistic fuzzy semi open set, intuitionistic fuzzy $\alpha$-open set, intuitionistic fuzzy pre-open set, intuitionistic fuzzy regular open set, intuitionistic fuzzy generalized open set, intuitionistic fuzzy generalized semi open set and intuitionistic fuzzy $\alpha$ generalized open set (IFSOS, IF $\alpha$ OS, IFPOS, IFROS, IFGOS, IFGSOS and I $\alpha$ FGOS) if the complement of $\mathrm{A}^{\mathrm{c}}$ is an IFSCS, IF $\alpha \mathrm{CS}$, IFPCS, IFRCS, IFGCS, IFGSCS and IF $\alpha$ GCS respectively.

\section{INTUITIONISTIC FUZZY WEAKLY GENERALIZED CLOSED SET}

In this section we introduce intuitionistic fuzzy weakly generalized closed set and have studied some of its properties.

Definition 3.1 An IFS A in an IFTS $(X, \tau)$ is said to be an intuitionistic fuzzy weakly generalized closed set (IFWGCS) if $\operatorname{cl}(\operatorname{int}(\mathrm{A})) \subseteq \mathrm{U}$ whenever $\mathrm{A} \subseteq \mathrm{U}, \mathrm{U}$ is IFOS in $\mathrm{X}$.

The family of all IFWGCSs of an IFTS $(X, \tau)$ is denoted by IFWGCS(X).

Example 3.2: Let $X=\{a, b\}$ and let $\tau=\left\{0_{\sim}, T, 1_{\sim}\right\}$ be an IFT on $\mathrm{X}$ where $\mathrm{T}=\langle\mathrm{x},(0.2,0.3),(0.8,0.7)\rangle$. Then the IFS $\mathrm{A}=\langle\mathrm{x},(0.2,0.2),(0.8,0.7)\rangle$ is an IFWGCS in $\mathrm{X}$.

Theorem 3.3: Every IFCS is an IFWGCS but not conversely.

Proof: Let $\mathrm{A}$ be an IFCS in $(\mathrm{X}, \tau)$.Let $\mathrm{U}$ be an intuitionistic fuzzy open set such that $A \subseteq U$. Since $A$ is intuitionistic fuzzy closed, $\operatorname{cl}(\mathrm{A})=\mathrm{A}$ and hence $\operatorname{cl}(\mathrm{A}) \subseteq \mathrm{U}$. But $\operatorname{cl}(\operatorname{int}(\mathrm{A})) \subseteq \mathrm{cl}(\mathrm{A}) \subseteq \mathrm{U}$. Therefore $\mathrm{cl}(\operatorname{int}(\mathrm{A})) \subseteq \mathrm{U}$. Hence A is an IFWGCS in $X$.

Example 3.4: Let $X=\{a, b\}$ and let $\tau=\left\{0_{\sim}, T, 1_{\sim}\right\}$ be an IFT on $X$, where $T=\langle x,(0.4,0.5),(0.6,0.5)\rangle$. Then the IFS $\mathrm{A}=\langle\mathrm{x},(0.2,0.3),(0.8,0.7)\rangle$ is an IFWGCS in $\mathrm{X}$ but not an IFCS in $\mathrm{X}$ since $\mathrm{cl}(\mathrm{A})=T^{c} \neq \mathrm{A}$.

Theorem 3.5: Every IF $\alpha$ CS is an IFWGCS but not conversely. Proof: Let $\mathrm{A}$ be an IF $\alpha \mathrm{CS}$ in $\mathrm{X}$ and let $\mathrm{A} \subseteq \mathrm{U}$ and $\mathrm{U}$ is an IFOS in $(\mathrm{X}, \tau)$. By hypothesis, $\operatorname{cl}(\operatorname{int}(\mathrm{cl}(\mathrm{A}))) \subseteq \mathrm{A}$. Therefore $\operatorname{cl}(\operatorname{int}((\mathrm{A})) \subseteq \operatorname{cl}(\operatorname{int}(\mathrm{cl}(\mathrm{A}))) \subseteq \mathrm{A} \subseteq \mathrm{U}$. Therefore $\operatorname{cl}(\operatorname{int}((\mathrm{A})) \subseteq \mathrm{U}$. Hence $A$ is an IFWGCS in $\mathrm{X}$.

Example 3.6: Let $X=\{a, b\}$ and let $\tau=\left\{0_{\sim}, T, 1_{\sim}\right\}$ be an IFT on $\mathrm{X}$ where $\mathrm{T}=\langle\mathrm{x},(0.5,0.3),(0.5,0.7)\rangle$. Then the IFS $\mathrm{A}=\langle\mathrm{x},(0.4,0.2),(0.6,0.8)\rangle$ is an IFWGCS but not an IF $\alpha \mathrm{CS}$ in $\mathrm{X}$ since $\mathrm{A} \subseteq \mathrm{T}$ but $\operatorname{cl}(\operatorname{int}(\operatorname{cl}(\mathrm{A})))=\langle\mathrm{x},(0.5,0.7),(0.5,0.3)\rangle \nsubseteq \subseteq \mathrm{A}$.

Theorem 3.7: Every IFGCS is an IFWGCS but not conversely.

Proof: Let $\mathrm{A}$ be an IFGCS in $\mathrm{X}$ and let $\mathrm{A} \subseteq \mathrm{U}$ and $\mathrm{U}$ is an IFOS in $(\mathrm{X}, \tau)$. Since $\operatorname{cl}(\mathrm{A}) \subseteq \mathrm{U}, \operatorname{cl}(\operatorname{int}(\mathrm{A})) \subseteq \operatorname{cl}(\mathrm{A})$. That is $\mathrm{cl}(\operatorname{int}(\mathrm{A})) \subseteq \mathrm{cl}(\mathrm{A}) \subseteq \mathrm{U}$. Therefore $\operatorname{cl}(\operatorname{int}(\mathrm{A})) \subseteq \mathrm{U}$.Hence $\mathrm{A}$ is an IFWGCS in $\mathrm{X}$. 
Example 3.8: Let $X=\{a, b\}$ and let $\tau=\left\{0_{\sim}, T, 1_{\sim}\right\}$ be an IFT on $\mathrm{X}$ where $\mathrm{T}=\langle\mathrm{x},(0.3,0.4),(0.7,0.6)\rangle$. Then the IFS $\mathrm{A}=\langle\mathrm{x},(0.2,0.4),(0.8,0.6)\rangle$ is an IFWGCS but not an IFGCS in $\mathrm{X}$ since $\mathrm{A} \subseteq \mathrm{T}$ but $\operatorname{cl}(\mathrm{A})=\langle\mathrm{x},(0.7,0.6),(0.3,0.4)\rangle \not \subseteq \mathrm{T}$.

Theorem 3.9: Every IFRCS is an IFWGCS but not conversely.

Proof: Let $\mathrm{A}$ be an IFRCS in $\mathrm{X}$ and let $\mathrm{A} \subseteq \mathrm{U}$ and $\mathrm{U}$ is an IFOS in $(\mathrm{X}, \tau)$. Since $\mathrm{A}$ is IFRCS, $\operatorname{cl}(\operatorname{int}(\mathrm{A}))=\mathrm{A} \subseteq \mathrm{U}$. This implies $\operatorname{cl}(\operatorname{int}(\mathrm{A})) \subseteq \mathrm{U}$. Hence $\mathrm{A}$ is an IFWGCS in $\mathrm{X}$.

Example 3.10: Let $X=\{a, b\}$ and let $\tau=\left\{0_{\sim}, T, 1_{\sim}\right\}$ be an IFT on $\mathrm{X}$, where $\mathrm{T}=\langle\mathrm{x},(0.6,0.8),(0.4,0.2)\rangle$. The IFS $\mathrm{A}=\langle\mathrm{x},(0.2,0.2),(0.7,0.8)\rangle$ is an IFWGCS but not an IFRCS in $\mathrm{X}$ since $\operatorname{cl}(\operatorname{int}(\mathrm{A}))=0_{\sim} \neq \mathrm{A}$.

Theorem 3.11: Every IFPCS is an IFWGCS but not conversely.

Proof: Let $\mathrm{A}$ be an IFPCS in $\mathrm{X}$ and let $\mathrm{A} \subseteq \mathrm{U}$ and $\mathrm{U}$ is an IFOS in $(X, \tau)$. By Definition, $\operatorname{cl}(\operatorname{int}(\mathrm{A})) \subseteq \mathrm{A}$ and $\mathrm{A} \subseteq \mathrm{U}$. Therefore $\operatorname{cl}(\operatorname{int}(\mathrm{A}) \subseteq \mathrm{U}$. Hence $\mathrm{A}$ is an IFWGCS in $\mathrm{X}$.

Example 3.12: Let $X=\{a, b\}$ and let $\tau=\left\{0_{\sim}, T, 1_{\sim}\right\}$ be an IFT on $\mathrm{X}$, where $\mathrm{T}=\langle\mathrm{x},(0.5,0.3),(0.5,0.7)\rangle$. Then the IFS $\mathrm{A}=\langle\mathrm{x},(0.9,0.3),(0.1,0.6)\rangle$ is an IFWGCS but not an IFPCS in $\mathrm{X}$ since $\operatorname{cl}(\operatorname{int}(\mathrm{A}))=T^{c} \not \subset \mathrm{A}$.

Theorem 3.13: Every IF $\alpha$ GCS is an IFWGCS but not conversely.

Proof: Let $A$ be an IF $\alpha$ GCS in $X$ and let $A \subseteq U$ and $U$ is an IFOS in $(X, \tau)$. By Definition, $A \cup \operatorname{cl}(\operatorname{int}(\operatorname{cl}(\mathrm{A}))) \subseteq \mathrm{U}$. This implies $\operatorname{cl}(\operatorname{int}(\operatorname{cl}(\mathrm{A}))) \subseteq \mathrm{U}$ and $\operatorname{cl}(\operatorname{int}(\mathrm{A})) \subseteq \operatorname{cl}(\operatorname{int}(\operatorname{cl}(\mathrm{A}))) \subseteq \mathrm{U}$. Therefore $\mathrm{cl}(\operatorname{int}(\mathrm{A})) \subseteq \mathrm{U}$. Hence $\mathrm{A}$ is an IFWGCS in X.

Example 3.14: Let $X=\{a, b\}$ and let $\tau=\left\{0_{\sim}, T, 1_{\sim}\right\}$ be an IFT on $\mathrm{X}$, where $\mathrm{T}=\langle\mathrm{x},(0.5,0.6),(0.5,0.4)\rangle$. Then the IFS $\mathrm{A}=\langle\mathrm{x},(0.3,0.5),(0.6,0.5)\rangle$ is an IFWGCS but not an IF $\alpha \mathrm{GCS}$ in $\mathrm{X}$ since $\alpha \operatorname{cl}(\mathrm{A})=1 \sim \not \Phi \mathrm{T}$.

Proposition 3.15: IFSCS and IFWGCS are independent to each other which can be seen from the following example.

Example 3.16: Let $X=\{a, b\}$ and let $\tau=\left\{0_{\sim}, T, 1_{\sim}\right\}$ be an IFT on $\mathrm{X}$, where $\mathrm{T}=\langle\mathrm{x},(0.4,0.3),(0.6,0.7)\rangle$. Then the IFS $\mathrm{A}=\mathrm{T}$ is an IFSCS but not an IFWGCS in $\mathrm{X}$ since $\mathrm{A} \subseteq \mathrm{T}$ but $\operatorname{cl}(\operatorname{int}(\mathrm{A}))=\langle\mathrm{x},(0.6,0.7),(0.4,0.3) \not \Phi \mathrm{T}$.

Example 3.17: Let $X=\{a, b\}$ and let $\tau=\left\{0_{\sim}, T, 1_{\sim}\right\}$ be an IFT on $\mathrm{X}$, where $\mathrm{T}=\langle\mathrm{x},(0.9,0.7),(0.1,0.2)\rangle$. Then the IFS $\mathrm{A}=\langle\mathrm{x},(0.7,0.6),(0.3,0.4)\rangle$ is an IFWGCS but not an IFSCS in $\mathrm{X}$ since $\operatorname{int}(\mathrm{cl}(\mathrm{A}))=1_{\sim} \not \subset \mathrm{A}$.

Proposition 3.18: IFGSCS and IFWGCS are independent to each other.

Example 3.19: Let $X=\{a, b\}$ and let $\tau=\left\{0_{\sim}, T, 1_{\sim}\right\}$ be an IFT on $\mathrm{X}$, where $\mathrm{T}=\langle\mathrm{x},(0.3,0.5),(0.7,0.5)\rangle$. Then the IFS $\mathrm{A}=\mathrm{T}$ is an IFWGCS but not an IFGPCS in $\mathrm{X}$ since $\mathrm{A} \subseteq \mathrm{T}$ but $\operatorname{cl}(\operatorname{int}(\mathrm{A})=\langle\mathrm{x},(0.7,0.5),(0.3,0.5)\rangle \not \subset \mathrm{A}$.

Example 3.20: Let $X=\{a, b\}$ and let $\tau=\left\{0_{\sim}, T, 1_{\sim}\right\}$ be an IFT on $\mathrm{X}$, where $\mathrm{T}=\langle\mathrm{x},(0.8,0.9),(0.2,0.1)\rangle$. Then the IFS $\mathrm{A}=\langle\mathrm{x},(0.7,0.8),(0.3,0.2)\rangle$ is an IFWGCS but not an IFGSCS in $\mathrm{X}$ since $\mathrm{scl}(\mathrm{A}))=1 \sim \not \subset \mathrm{T}$.
Remark 3.21: The union of any two IFWGCSs need not be an IFWGCS in general as seen from the following example.

Example 3.22: Let $X=\{a, b\}$ be an IFTS and let $\mathrm{T}=\langle\mathrm{x},(0.6,0.8),(0.4,0.2)\rangle$. Then $\tau=\left\{0_{\sim}, \mathrm{T}, 1_{\sim}\right\}$ is an IFT on $\mathrm{X}$ and the IFSs $\mathrm{A}=\left\langle\mathrm{X}, \quad\left(\begin{array}{lll}0.1 & , 0.8),(0.9,0.2)\end{array}\right\rangle\right.$, $\mathrm{B}=\langle\mathrm{x},(0.6,0.7),(0.4,0.3)\rangle$ are IFWGCSs but $\mathrm{A} \cup \mathrm{B}$ is not an IFWGCS in X.

The following implications are true:

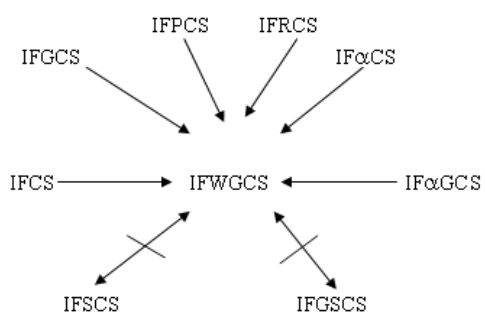

Fig.1 Relation between intuitionistic fuzzy weakly generalized closed set and other existing intuitionistic fuzzy closed sets

In this diagram by "A $\rightarrow$ B" we mean A implies B but not conversely and "A $\longleftrightarrow \mathrm{B}$ " means $\mathrm{A}$ and $\mathrm{B}$ are independent of each other.

None of them is reversible.

\section{INTUITIONISTIC FUZZY WEAKLY GENERALIZED OPEN SET}

In this section we introduce intuitionistic fuzzy weakly generalized open set and have studied some of its properties.

Definition 4.1: An IFS A is said to be an intuitionistic fuzzy weakly generalized open set (IFWGOS in short) in $(X, \tau)$ if the complement $\mathrm{A}^{\mathrm{c}}$ is an IFWGCS in $\mathrm{X}$.

The family of all IFWGOS of an IFTS $(X, \tau)$ is denoted by $\operatorname{IFWGO}(\mathrm{X})$.

Example 4.2: Let $X=\{a, b\}$ and let $\tau=\left\{0_{\sim}, T, 1_{\sim}\right\}$ be an IFT on $\mathrm{X}$, where $\mathrm{T}=\langle\mathrm{x},(0.7,0.5),(0.2,0.5)\rangle$. Then the IFS $\mathrm{A}=\langle\mathrm{x},(0.8,0.7),(0.2,0.2)\rangle$ is an IFWGOS in $\mathrm{X}$.

Theorem 4.3: For any $\operatorname{IFTS}(X, \tau)$, we have the following:

(i)Every IFOS is an IFWGOS.

(ii)Every IFSOS is an IFWGOS.

(iii)Every IF $\alpha \mathrm{OS}$ is an IFWGOS.

(iv)Every IFGOS is an IFWGOS. But the converses are not true in general.

Proof: Straight forward.

The converse of the above statement need not be true in general which can be seen from the following examples.

Example 4.4: Let $X=\{a, b\}$ and $T=\langle x,(0.7,0.5),(0.3,0.4)\rangle$. Then $\tau=\left\{0_{\sim}, \mathrm{T}, 1_{\sim}\right\}$ is an IFT on $\mathrm{X}$. The IFS $\mathrm{A}=\langle\mathrm{x},(0.8,0.7)$, $(0.1,0.2)\rangle$ is an IFWGOS in $(X, \tau)$ but not an IFOS in $X$. 
Example 4.5: Let $\mathrm{X}=\{\mathrm{a}, \mathrm{b}\}$ and let $\tau=\left\{0_{\sim}, \mathrm{T}, 1_{\sim}\right\}$, where $\mathrm{T}=\langle\mathrm{x}, \quad(0.1,0.2), \quad(0.9,0.7)\rangle$. Then the IFS $\mathrm{A}=\langle\mathrm{x},(0.3,0.4),(0.7,0.6)\rangle$ is an IFWGOS but not an IFSOS in $\mathrm{X}$.

Example 4.6: Let $X=\{a, b\}$ and let $\tau=\left\{0_{\sim}, T, 1_{\sim}\right\}$ be an IFT on $\mathrm{X}$, where $\mathrm{T}=\langle\mathrm{x},(0.5,0.7),(0.5,0.3)\rangle$. Then the IFS $\mathrm{A}=\langle\mathrm{x},(0.6,0.8),(0.4,0.2)\rangle$ is an IFWGOS but not an $\mathrm{IF} \alpha \mathrm{OS}$ in $X$.

Example 4.7: Let $X=\{a, b\}$ and $T=\langle x,(0.6,0.5),(0.4,0.5)\rangle$. Then $\tau=\left\{0_{\sim}, \mathrm{T}, 1_{\sim}\right\}$ is an IFT on $\mathrm{X}$. The IFS $\mathrm{A}=\langle\mathrm{x},(0.7,0.6),(0.3,0.4)\rangle$ is an IFWGOS but not an IFPOS in $X$.

Remark 4.8: The intersection of any two IFWGOSs need not be an IFWGOS in general.

Example 4.9: Let $X=\{a, b\}$ be an IFTS and let $\mathrm{T}=\langle\mathrm{x},(0.6,0.8),(0.4,0.2)\rangle$.Then $\tau=\left\{0_{\sim}, \mathrm{T}, 1_{\sim}\right\}$ is an IFT on $\mathrm{X}$. The IFSs $\mathrm{A}=\left\langle\mathrm{x}, \quad(0.9,0.2),\left(\begin{array}{ll}0.1, & 0.8)\rangle \text { and }\end{array}\right.\right.$ $\mathrm{B}=\langle\mathrm{x},(0.4,0.3),(0.6,0.7)\rangle$ are IFWGOS's but $\mathrm{A} \cap \mathrm{B}$ is not an IFWGOS in $\mathrm{X}$

Theorem 4.10: An IFS A of an IFTS $(X, \tau)$ is an IFWGOS if and only if $\mathrm{F} \subseteq \operatorname{int}(\mathrm{cl}(\mathrm{A}))$ whenever $\mathrm{F}$ is an IFCS and $\mathrm{F} \subseteq \mathrm{A}$.

Proof: Necessity: Suppose A is an IFWGOS in X. Let $\mathrm{F}$ be an IFCS and $F \subseteq A$. Then $F^{c}$ is an IFOS in $X$ such that $A^{c} \subseteq F^{c}$. Since $A^{c}$ is an IFWGCS, $\operatorname{cl}\left(\operatorname{int}\left(A^{c}\right)\right) \subseteq F^{c}$. Hence $(\operatorname{int}(\operatorname{cl}(A)))^{c} \subseteq F^{c}$. This implies $\mathrm{F} \subseteq \operatorname{int}(\mathrm{cl}(\mathrm{A}))$.

Sufficiency: Let $\mathrm{A}$ be an IFS of $\mathrm{X}$ and let $\mathrm{F} \subseteq \operatorname{int}(\mathrm{cl}(\mathrm{A}))$ whenever $\mathrm{F}$ is an IFCS and $\mathrm{F} \subseteq \mathrm{A}$. Then $\mathrm{A}^{\mathrm{c}} \subseteq \mathrm{F}^{\mathrm{c}}$ and $\mathrm{F}^{\mathrm{c}}$ is an IFOS. By hypothesis, $(\operatorname{int}(\operatorname{cl}(A)))^{c} \subseteq \mathrm{F}^{c}$. Hence $\operatorname{cl}\left(\operatorname{int}\left(\mathrm{A}^{\mathrm{c}}\right)\right) \subseteq \mathrm{F}^{\mathrm{c}}$. Hence $\mathrm{A}$ is an IFWGOS of $\mathrm{X}$.

\section{APPLICATIONS OF INTUITIONISTIC FUZZY WEAKLY GENERALIZED CLOSED SET}

In this section, we introduce intuitionistic fuzzy ${ }_{\mathrm{w}} \mathrm{T}_{1 / 2}$ space and ${ }_{w g} T_{q}$ space, which utilize intuitionistic fuzzy weakly generalized closed set and its characterizations are proved.

Definition 5.1: An IFTS $(X, \tau)$ is called an intuitionistic fuzzy ${ }_{\mathrm{w}} \mathrm{T}_{1 / 2}\left(\mathrm{IF}_{\mathrm{w}} \mathrm{T}_{1 / 2}\right.$ in short) space if every IFWGCS in $\mathrm{X}$ is an IFCS in $\mathrm{X}$.

Definition 5.2: An IFTS $(X, \tau)$ is called an intuitionistic fuzzy ${ }_{w g} T_{q}$ (IF ${ }_{w g} T_{q}$ in short) space if every IFWGCS in X is an IFPCS in X.

Theorem 5.3: Every $\mathrm{IF}_{\mathrm{w}} \mathrm{T}_{1 / 2}$ space is an $\mathrm{IF}_{w g} T_{q}$ space. But the converse is not true in general.

Proof: Let $\mathrm{X}$ be an $\mathrm{IF}_{\mathrm{w}} \mathrm{T}_{1 / 2}$ space and let $\mathrm{A}$ be an IFWGCS in $\mathrm{X}$. By hypothesis A is an IFCS in X. Since every IFCS is an IFPCS, $\mathrm{A}$ is an IFPCS in X. Hence $\mathrm{X}$ is an $\mathrm{IF}_{w g} T_{q}$ space.

The converses need not be true which can be seen from the following examples.
Example 5.4: Let $X=\{a, b\}$ and let $\tau=\left\{0_{\sim}, T, 1_{\sim}\right\}$ where $\mathrm{T}=\langle\mathrm{x},(0.9,0.9),(0.1,0.1)\rangle$. Then $(\mathrm{X}, \tau)$ is an $\mathrm{IF}{ }_{w g} T_{q}$ space. But it is not an $\mathrm{IF}_{\mathrm{w}} \mathrm{T}_{1 / 2}$ space since the IFS $\mathrm{A}=\langle\mathrm{x},(0.2,0.3)$, $(0.8,0.7)\rangle$ is IFWGCS but not IFCS in X.

Theorem 5.5: Let $(X, \tau)$ be an IFTS and $X$ is an $\operatorname{IF}_{w} T_{1 / 2}$ space then

(i) Any union of IFWGCS is an IFWGCS.

(ii) Any intersection of IFWGOS is an IFWGOS.

Proof:

(i): Let $\left\{A_{i}\right\}_{i \in J}$ be a collection of IFWGCS in an ${ }_{w} T_{1 / 2}$ space $(\mathrm{X}, \tau)$. Therefore every IFWGCS is an IFCS. But the union of IFCS is an IFCS. Hence the Union of IFWGCS is an IFWGCS in $\mathrm{X}$.

(ii): It can be proved by taking complement in (i).

Theorem 5.6: An IFTS $X$ is an $\mathrm{IF}_{w g} T_{q}$ space if and only if $\operatorname{IFWGOS}(\mathrm{X})=\operatorname{IFPOS}(\mathrm{X})$.

Proof: Necessity: Let $A$ be an IFWGOS in $X$. Then $A^{c}$ is an IFWGCS in X. By hypothesis $\mathrm{A}^{\mathrm{c}}$ is an IFPCS in X. Therefore A is an IFPOS in $\mathrm{X}$. Hence IFWGOS(X) $=\operatorname{IFPOS}(\mathrm{X})$.

Sufficiency: Let $A$ be an IFWGCS in $X$. Then $A^{c}$ is an IFWGOS in X. By hypothesis $\mathrm{A}^{\mathrm{c}}$ is an IFPOS in X. Therefore A is an IFPCS in X. Hence $\mathrm{X}$ is an IF ${ }_{w g} T_{q}$ space.

Theorem 5.7: An IFTS $X$ is an IF ${ }_{w} T_{1 / 2}$ space if and only if $\operatorname{IFWGOS}(\mathrm{X})=\operatorname{IFOS}(\mathrm{X})$.

Proof: Necessity: Let A be an IFWGOS in $X$. Then $A^{c}$ is an IFWGCS in X. By hypothesis $\mathrm{A}^{\mathrm{c}}$ is an IFCS in X. Therefore A is an IFOS in $\mathrm{X}$. Hence IFWGOS $(\mathrm{X})=\operatorname{IFOS}(\mathrm{X})$.

Sufficiency: Let $A$ be an IFWGCS in $X$. Then $A^{c}$ is an IFWGOS in X. By hypothesis $\mathrm{A}^{\mathrm{c}}$ is an IFPOS in X. Therefore $\mathrm{A}$ is an IFPCS in $X$. Hence $X$ is an $\operatorname{IF}_{w} T_{1 / 2}$ space.

\section{CONCLUSION}

In this paper we have introduced a new class of intuitionistic fuzzy closed set namely intuitionistic fuzzy weakly generalized closed set and have studied the relationship between intuitionistic fuzzy weakly generalized closed set and other existing intuitionistic fuzzy closed sets. Also we have investigated some of the properties of intuitionistic fuzzy weakly generalized closed set. As an application of intuitionistic fuzzy weakly generalized closed set we have introduced two new spaces namely intuitionistic fuzzy ${ }_{\mathrm{w}} \mathrm{T}_{1 / 2}\left(\mathrm{IF}_{\mathrm{w}} \mathrm{T}_{1 / 2}\right.$ in short $)$ space and intuitionistic fuzzy ${ }_{w g} T_{q}$ (IF ${ }_{w g} T_{q}$ in short) space and studied some of their properties.

\section{REFERENCES}

[1] K.T.Atanassov, "Intuitionistic fuzzy sets", Fuzzy Sets and Systems, 20 (1986), 87-96.

[2] P.Bhattacharyy a and B.K.Lahiri, "Semi generalized closed sets in topology", Indian J. Math, 29(1987), 375-382.

[3] C.L.Chang, "Fuzzy topological spaces", J.Math.Anal.Appl, 24(1968), 182-190. 
[4] D.Coker, "An introduction to intuitionistic fuzzy topological spaces", Fuzzy sets and systems, 88(1997), 8189

[5] H.Gurcay, A.Hay dar and D.Coker, "On fuzzy continuity in intuitionistic fuzzy topological spaces", jour. of fuzzy math, 5(1997), 365-378.

[6] I.M.Hanafy, "Intuitionistic fuzzy $\gamma$ continuity", Canad. Math Bull. XX (2009), 1-11.

[7] C.Mukundhan and N.Nagaveni, "A Weaker form of a Generalized closed set", Int.J.Contemp.Math.Sciences, 20(2011), 949-961.

[8] N.Nagaveni, "Studies on generalized on homeomorphisms in topological spaces", Ph.D Thesis, Bharathiar University, Coimbatore 1999.

[9] K.Sakthivel, "Intuitionistic fuzzy alpha generalized closed sets" (submitted).
[10] R.Santhi and K. Sakthivel, "Intuitionistic fuzzy generalized semi continuous mappings" (submitted).

[11] T.Shyla Isac Mary and P.Thangavelu, "On Regular Pre-Semiclosed Sets in Topological Spaces", KBM Journal of Mathematical Sciences \& Computer Applications, 1(2010), 9-17.

[12] S.S.Thakur and Rekha Chaturvedi, "R.G-closed sets in intuitionistic fuzzy topological spaces", Universitatea Din Bacau Studii Si Cercertar Stiintifice, 6(2006), 257-272.

[13] Young Bae Jun and Seok-Zun Song, "Intuitionistic fuzzy semi-pre open sets and Intuitionistic semi-pre continuous mappings", Jour.of Appl.Math and Computing, 19(2005), 464-474.

[14] L.A.Zadeh, "Fuzzy sets", Information control, 8 (1965), 338-353. 